\title{
Effectiveness of Cognitive-Behavior Therapy on Cognitive Flexibility in Perfectionist
}

\author{
Rashin Sabri Nazarzadeh1, Mozhgan Fazeli'2, Mozhgan Meamarbashi Aval'3, \\ Rahele Maddah Shourche ${ }^{4}$ \\ ${ }^{1}$ Department of Psychology, Payam Nur University of Abadan, Abadan, Iran \\ ${ }^{2}$ Department of Psychology, Islamic Azad University, Ahvaz Branch, Iran \\ ${ }^{3}$ Department of Psychology, Payam Nur University of Kashmar, Kashmar, Iran \\ ${ }^{4}$ Faculty of Education and Psychology, Ferdowsi University of Mashhad, Mashhad, Iran \\ Email: rahele.maddah@gmail.com
}

Received 10 September 2015; accepted 30 October 2015; published 3 November 2015

Copyright (C 2015 by authors and Scientific Research Publishing Inc.

This work is licensed under the Creative Commons Attribution International License (CC BY). http://creativecommons.org/licenses/by/4.0/

c) (i) Open Access

\begin{abstract}
The purpose of this study was to investigate the effectiveness of the cognitive behaviour therapy on the perfectionist students' cognitive flexibility. The population in the research included students of Khorramshahr University of Marine Science and Technology on 2014 that were high perfectionism. In this study by using a Purposive sampling we included 31 students among whom were perfectionism based on FMPS scale. Method of research was semi-experimental study and the type of pre-test and post test with control and instrumentals of study was cognitive flexibility questionnaire, perfectionism of frost. First, pretests are completed by both groups. After the group therapy (which consisted of eight ninety-minute sessions) was finished, the post-test was carried out for both control and experimental groups. After the group therapy (which consisted of eight ninety-minute sessions) was finished, the post-test was carried out for both control and experimental groups. For the analysis of data, Analysis of MANCOVA was used to analyze data. Results showed that the cognitive behavior therapy has affected on cognitive flexibility and decreased perfectionism. These results had continued in stage of following up. Conclusions increased perfectionism of student by improving their cognitive flexibility and these had continued because of practice in stage of following up.
\end{abstract}

\section{Keywords}

Cognitive Behavior Therapy, Cognitive Flexibility, Perfectionism

\section{Introduction}

Perfectionism is a personal characteristic which in recent decades has been the subject of many studies (Mitchell,

How to cite this paper: Nazarzadeh, R. S., Fazeli, M., Aval, M. M., \& Shourche, R. M. (2015). Effectiveness of CognitiveBehavior Therapy on Cognitive Flexibility in Perfectionist. Psychology, 6, 1780-1785.

http://dx.doi.org/10.4236/psych.2015.614174 
Newall, Broeren, \& Hudson, 2013; Besser, Flett, \& Hwitt, 2004). Fersot (quoting from Rekabdar \& Solcimani, 2011) described Perfectionism as devising rigid personal criteria for performance and also being too much critical in evaluating his/her own performance, Albert Alic considers perfectionism as one of the gates to illogical beliefs which lead to psychological unrest (Sahraee, Khosravi, \& Besharat, 2009). Perfectionists have stable and fixed beliefs and the inflexibility and rigidity of beliefs is one of the main characteristics of perfectionists (Sahraee et al., 2009). The inflexibility of beliefs, too much adherence to the rigid criteria, and self-criticism are indications of weakness in the individual's cognitive flexibility. Cognitive flexibility improves the individual's ability in changing the direction of cognitions and compatibility with environmental demands (Dennis \& Vander War, 2010). Gunduz (2013), in a study regarding cognitive flexibility, found out that the individuals with high cognitive flexibility are easily compatible with environmental demands and handle difficult situations and create substitute ideas, thoughts and utilize problem-solving skills, therefore cognitive flexibility plays an important role in humans' cognitive health and his/her growth process. Whereas studies are indicative of the face that perfectionists, via being displeased with their performance, ruminating their thoughts, and paying too much attention to assignments, determine their cognitive style and conditions (Kakavand, Lebadi, \& Zaree, 2013; Lloyd, Yiend, Schmidt, \& Tchanturia, 2014; Besser et al., 2004). Beck believes that people's experience results in the formation of their beliefs and assumptions are used in perception organization also behavior control, if these assumptions be inflexible and extremist, then they are inefficient; if be activated they arouse unconscious negative thoughts (Forozande, Delaram, Solati, Ayin, \& Deris, 2002).

\subsection{Cognitive-Behavior Therapy}

In Cognitive-Behavior Therapy (CBT), the individual attains cognitive flexibility and when confronting such destructive beliefs and assumptions, instead of surrendering, he/she challenges and investigates then from all aspects (Mitchell et al., 2013). This therapy provides the individual with extensive information and new experiences of present-past events. Therefore, the individual has more options and accordingly, trains CBT, evaluation skills, and a range of standard confronting cognitive-behavioral skills to be guideline for flexibility in choosing the approaches which are appropriate to the situation (Gan, Zhang, Wang, \& Shen, 2006).

\subsection{The Present Study}

Because the basic assumption in CBT is that bias in thinking causes cognitive disorders also emphasizes the pivotal role of inefficient beliefs and cognitive distortions (Mohamdkhani, 2011). On the other hand, the basic principle in CBT is to eradicate inefficient unconscious cognitions and substitute. Them with realistic efficient cognitions that with improving the individuals' cognitive flexibility causes their treatment (Soltani et al., 2013). Therefore, the present study aims to investigate the effectiveness of changing beliefs, recognizing, and confronting with cognitive distortions on perfectionist flexibility also their performances. There is the possibility that instructing some of the basic cognitive skills improve the cognitive flexibility of those who have signs of perfectionism, if the findings of this study confirm this possibility; then besides enhancing the knowledge regarding the relation between changing inefficient beliefs and cognitive defects with perfectionism via cognitive flexibility, an approach for improving cognitive flexibility is approved.

\section{Method}

The present study is a Pre-test/Post-test control group design (semi- experimental study).

\subsection{Participants}

The participants were all students of Marine Sciences and Technology University of Khramshahr in 2012-2013 academic year. The total number of the students was 16,543 and via targeted sampling 31 students (15 in each group) were selected. It should be mentioned and noticed that Delavar considers 15 students for each group (Delavar, 2006). The mean ages in experimental group were $M=21.67(S D=1.51)$ years old (the age range: 18 - 28) and in control group were $M=21.55(S D=2.55$ ) years old (the range age: 18 - 25). The experimental group was 11 native people (Abadan-Khoramshahr) \& 5 non-native people (number of married $=3$; number of single: 13). The control group was 9 native people (Abadan-Khoramshahr) \& 6 non-native people (number of married $=2$; number of single: 13 ). At first, all the students were asked to fill out the perfectionism question- 
naire, each student was given a code and they were asked to provide their phone number to be invited for the second stage of the study. After scoring the questionnaires, the qualified candidates - those with perfectionism scoring above 90 that indicates more sings of perfectionism-were invited for the second stage of the study to fill out the cognitive flexibility questionnaire (the lowest score was 84). At this stage using random method (15 students were placed in control group; 16 in experimental group). Before filling out the cognitive questionnaire by the participants, it was explained to them that this is a research study also the information they provide will be used demographically not in case study, and some of the achievements of the study such as awareness, sympathy regarding perfectionism between the group members were informed to participate in the groups. The independent variable (CBT) was conducted in two months (eight ninety-minute-session) for experimental group. During this period, the control group didn't receive any cognitive training. Then effectiveness of this kind of therapy on the cognitive flexibility of perfectionists was investigated by asking the participants to fill out both the cognitive flexibility \& Perfectionism questionnaires again one month after the compellation of therapy interference.

\subsection{Instrument}

Dennis \& Vander Wal Cognitive Flexibility Inventory (CFI) (2010). This questionnaire is a short self-reported instrument which contains 20 questions. It is used to assess that kind of cognitive flexibility which is essential for the individuals to successfully challenge and substitute the inefficient thoughts with efficient ones. It is scored based on likert 7 point scale. This questionnaire is also used for evaluating the individuals' clinical and non-clinical progress, the individuals' improvement in creating flexible thinking in CBT for depression and other mental diseases. Simultaneous-validity of this questionnaire with Beck's depression (BDI-II) was -0/39, its convergence-validity with Martin-Robin's cognitive flexibility scale was 0.75 (Dennis \& Vander Wal, 2010). In Iran, sharre and et al. (cited from Soltani, Sharre, Bahreinian, \& Farmain, 2013) reported validity coefficient for retesting the total scale equal to 0.71 \& Cronbach's alpha coefficient of the total scale 0.90 . In Iran CFI also benefits a desirable simultaneous, convergence, and factor validity. Its convergence validity with Resilience questionnaire was 0.67; its simultaneous validity with BDI-II questionnaire was -0.50 (Soltani et al., 2013). Frost Multidimensional Perfectionism Scale (1990): This scale containers 35 questions which is scorned using Likert 5 point method ( 1 = completely agree; 5 = completely disagree). Reliability coefficient of Cronbach's alpha is 0.83, and Goodness of Fit of this questionnaire according to its confirming factor analysis is GFI = 0.9, and Root Mean Square Error of Approximation is RMSEA < 0.05 (Soleimani \& Rekabdar, 2011).

\section{Result}

In this study, descriptive statistical approaches were used to calculate the scores' mean \& standard deviation. In order to compare the groups also the effectiveness of the therapy, the date of this study were analyzed using SPSS 16, and ANCOVA and MANCOVA statistical approaches. The descriptive findings of this study i.e., mean standard deviation, the number of the sample participants for all variables of this study are presented in Table 1.

According to Table 1, in pre-test, the means and standard deviations of cognitive flexibility also perfectionism were approximately equal in the two groups. In post-test in comparison with the control group-the mean and standard deviation of the cognitive flexibility of the experimental group improved also perfectionism decreased. All of the participants of the two groups cooperated with the researchers until the study was finished.

As Table 2 shows, with controlling pre-test, the significant levels of indicative of the fact that there is significant difference between the control and experimental groups. In all of the tests, the significant level is 0.0001 that, according to Multi-Variables Covariance Test, is indicative of the fact that there is a significant difference in the groups mean. To investigate which variable differs in the two groups, one way variance analysis was performed. The results are given in Table 3 . The effect size (difference) is 0.73 that means 0.73 of the individual differences in perfections and cognitive flexibility post-test was related to the effect of cognitive-behavioral therapy. Statistical power equals 1 that means there was no possibility of the type 2 error.

The table of One-Way Variance analysis shows that cognitive flexibility $(P<0.0001, \mathrm{~F}=32.74)$ also Perfectionism $(P<0.0001, \mathrm{~F}=31.90)$ were different in the two groups which is indicative of the fact that the therapy was effective for the experimental group.

In order to investigate the reliability of the effect of the CBT, after 4 weeks, the participants of the two groups were asked to be reexamined as follow-up stage. The results of date analysis are reported in the following. 
Table 1. Estimated marginal means \& standard deviation in Pre-Post Test \& follow up.

\begin{tabular}{ccccccccc}
\hline & & \multicolumn{2}{c}{ Pre-Test } & \multicolumn{2}{c}{ Post-Test } & \multicolumn{2}{c}{ Follow up } \\
\cline { 2 - 8 } & & $\mathrm{E}^{\mathrm{b}}$ & $\mathrm{C}^{\mathrm{c}}$ & $\mathrm{E}$ & $\mathrm{C}$ & $\mathrm{E}$ & $\mathrm{C}$ \\
\cline { 2 - 9 } & $\boldsymbol{n}^{\boldsymbol{a}}$ & 16 & 15 & 16 & 15 & 16 & 15 \\
\hline \multirow{2}{*}{ Cognitive Flexibility } & $\mathrm{M}^{\mathrm{d}}$ & 97.93 & 94.60 & 117.01 & 95.53 & 116.12 & 92.13 \\
& $\mathrm{SD}^{\mathrm{e}}$ & 10.99 & 13.42 & 10.52 & 12.02 & 9.57 & 9.82 \\
\cline { 3 - 8 } perfectionist & $\mathrm{M}$ & 116 & 104.08 & 96.06 & 106.07 & 14.06 & 107.47 \\
& $\mathrm{SD}$ & 16.66 & 14.11 & 8.69 & 12.97 & 9.77 & 7.06 \\
\hline
\end{tabular}

${ }^{\mathrm{a}}$ namber of sample; ${ }^{\mathrm{b}}$ expremental; ${ }^{\mathrm{c}}$ control; ${ }^{\mathrm{d}}$ mean; ${ }^{\mathrm{e}}$ standard deviation.

Table 2. Analysis of MANCOVA with pre-test control.

\begin{tabular}{|c|c|c|c|c|c|c|c|}
\hline & Value & $\mathrm{F}$ & $\mathrm{DF}_{\text {error }}$ & $\mathrm{DF}_{\text {hypo }}$ & $P$-Value & Eta & Power \\
\hline Pillai's Trace & 0.72 & 34.92 & 2 & 26 & 0.0001 & 0.73 & 1 \\
\hline Wilks’ Lambda & 0.27 & 34.92 & 2 & 26 & 0.0001 & 0.73 & 1 \\
\hline Hotelling's Trace & 2.6 & 34.92 & 2 & 26 & 0.0001 & 0.73 & 1 \\
\hline Roy’s Largest Root & 2.6 & 34.92 & 2 & 26 & 0.0001 & 0.73 & 1 \\
\hline
\end{tabular}

Table 3. Analysis of one-way variance of cognitive flexibility \& perfectionist.

\begin{tabular}{ccccccccccc}
\hline & Sum of Square & DF & Mean Square & F & P-Value & Eta & Power & DF error \\
\hline Cognitive flexibility & 2711 & 1 & 2711 & 32.74 & 0.0001 & 0.55 & 1 \\
Perfectinist & 1780 & 1 & 1780 & 31.90 & 0.0001 & 0.54 & 1 \\
\hline
\end{tabular}

As Table 4 shows with controlling pre-test, the significant levels of all tests are indicative of the fact that there is a significant difference between the students of the control and experimental group. In all of the tests, the significant level is also 0.0001 that, according to the Multi-Variable Covariance Test, is indicative of the fact that there is a significant difference in the groups' mean. One-Way Variance analysis is given in Table 5. The effect size is 0.82 that means 0.82 of the individual differences in perfectionism and cognitive flexibility posttest scores relating to the effect of the CBT has been preserved. Statistical power equals 1 that means there was no possibility of the type 2 error.

The table of One-Way Variance analysis of follow-up stage also show, that cognitive flexibility $(P<0.0001$, $\mathrm{F}=65.59)$ and perfectionism $(P<0.0001, \mathrm{~F}=35 / 49)$ were different in the two groups which is indicative of the fact that the therapy is effective for the experimental group also that therapy's effectiveness was long lasting.

\section{Discussion}

The present study investigated the effectiveness of Cognitive-Behavioral Therapy on the perfectionists' cognitive flexibility, because according to some studies (Glass, Maddox, \& Love, 2013) human's brain has the ability to learn new behaviors, form memory in the brain, and change the perceptions during the life, and it seems that perfectionists besides having information and even behavioral abilities, they adhere to some behaviors, beliefs and follow them persistently (Sahraee et al., 2010; Basser et al., 2004).

The finding of the present study was indicative of the fact that the CBT was effective on the cognitive flexibility of perfectionists. This finding confirms the previous studies (Gunduz, 2013; Mitchell et al., 2013). Regarding to the fact that cognitive flexibility improves the individual's ability in changing the direction of cognitions and compatibility with environmental demands (Dennis \& Wander Wal, 2010). Perfectionists use such ability that requires cognitive rotations very few, and also pointing to the fact that CBT provides the individual with extensive information and new experiences of the present-past events (Gan et al., 2006). It seems that this 
Table 4. Analysis of MANCOVA with controlling pre-test in follow up stage.

\begin{tabular}{cccccccc}
\hline & Value & $\mathrm{F}$ & $\mathrm{DF}_{\text {error }}$ & $\mathrm{DF}_{\text {hypo }}$ & P-Value & Eta & Power \\
\hline Pillai's Trace & 0.82 & 57.63 & 2 & 26 & 0.0001 & 0.82 & 1 \\
Wilks' Lambda & 0.18 & 57.63 & 2 & 26 & 0.0001 & 0.82 & 1 \\
Hotelling's Trace & 4.43 & 57.63 & 2 & 26 & 0.0001 & 0.82 & 1 \\
Roy's Largest Root & 4.43 & 57.63 & 2 & 26 & 0.0001 & 0.82 & 1 \\
\hline
\end{tabular}

Table 5. Analysis of one-way variance of cognitive flexibility \& perfectionist.

\begin{tabular}{cccccccccc}
\hline & Sum of Square & DF & Mean Square & F & P-Value & Eta & Power & DF error \\
\hline Cognitive flexibility & 4070 & 1 & 4070 & 65.59 & 0.0001 & 0.71 & 1 & 27 \\
Perfectinist & 2080 & 1 & 2080 & 35.49 & 0.0001 & 0.57 & 1 & 27 \\
\hline
\end{tabular}

therapy gives the individual more choices and based on this trains CBT, evaluation skills, and a range of standard cognitive-behavioral confrontation skills to be a guide for flexibility in choosing approaches that suits the situation (Gan et al., 2006).

Soltani et al. (2013) found out that CBT, with improving cognitive flexibility, can arouse more compatible confrontation styles. The cognitive therapy is based on a cognition system which is an open structure that means it is possible at any time new facts, new experiences, even new needs and preferences arouse which are appropriate to the need of the individual (Fati et al., 2011). Cognitive techniques, recognizing and challenging negative thoughts are endeavor to find substitute thinking ways, using this method causes change in the individual's cognitive system which leads into changing his/her reactions by cognitive qualities and the individual can correctly understand also interpret the truths (Kahrizi, Aghayusefi, \& Mirhashemi, 2011).

The present study, based on the exiting finding, practical knowledge, with emphasizing on the cognitive approaches and using cognitive techniques, could prevent the participants from choosing inefficient thinking style also confer the individual the skill for choosing different thinking styles. It also helped the individual, using the required techniques, to create a mental rotation and release themselves from the pressure. As the study shows, the participants could dismiss their present behaviors, thoughts and by using profit-loss technique, voluntary inhibitory cortex, also using the contrary beliefs, they could experience new conditions and more options. This trend gives them new experiences; they can break the always vicious circle of the results of their own thoughts, behaviors, beside negative prejudices; they consider other possibilities; they decrease overgeneralizing the failures to all situations. The participants, using award-punish technique, even after the group therapy was finished, successfully preserved their accomplishments in the group. In addition these skills, their self-conscious about behavioral motivations also not achieving the desired result although consistently endeavoring especially in interpersonal relations, helped them to change the present status and utilize the cognitive flexibility.

Regarding to the fact that in the sample of this study, the participants, were all native, non-notice, from different fields of study; their free time was also different; the groups were coordinated by changing the time schedule during the day. For the full participation of all students the group therapy was conducted during the academic semester. At this time the students were mostly involved and obsessed with their studies; but the best time for group therapy, also for self-evaluation, is when students are free of education (they are in holiday).

\section{Acknowledgements}

We thank students of Khorramshahr University of Marine Science and Technology (2014) for cooperation in research.

\section{References}

Besser, A., Flett, G. L., \& Hewitt, P. (2004). Perfectionism, Cognition and Affect in Response to Performance Fallure vs. Success. Rational-Emotive \& Cognitive-Behavior Therapy, 22, 301-326. 
Delavar, A. (2006). Research Methodologies in Psychology and Training ya Education Science. Tehran Publication: Payamnur University.

Dennis, J. P., \& Vander Wal, J. S. (2010). The Cognitive Flexibility Inventory: Instrument Development and Estimates of Reliability and Validity. Cognitive Therapy and Research, 34, 241-253. http://dx.doi.org/10.1007/s10608-009-9276-4

Fati, L., Shakiba, S. H., Tahmasebi Moradi, S. H., Naseri, H., \& Ziaee, H. (2011). Technique of Cognitive Therapy (p. 19). Tehran: Danzhe.

Forozande, N., Del Aram, M., Solati, K., Aeen, F., \& Deris, F. (2002). Effect of Cognitive-Behavior Therapy on Depression of Non-Medical College Student. Journal of Shahrekord University of Medical Sciences, 4, 11-17.

Gan, Y., Zhang, Y., Xilin, W., Wang, S., \& Shen, X. (2006). The Coping Flexibility of Neurasthenia and Depressive Patients. Personality and Individual Differences, 40, 859-871. http://dx.doi.org/10.1016/j.paid.2005.09.006

Glass, B. D., Maddox, W. T., \& Love, B. C.(2013). Real-Time Strategy Game Training: Emergence of a Cognitive Flexibility Trait. Plosone, 8, 1-7. http://dx.doi.org/10.1371/journal.pone.0070350

Gunduz, B. (2013). Emotional Intelligence, Cognitive Flexibility and Psychological Symptoms in Pre-Service Teachers. Durational Research and Reviews, 8, 1048-1056.

Kahrizi, H., Aghayusefi, A., \& Mirhashemi, M. (2011). Effect of Cognitive-Group-Therapy (Michael Frre) on Decrease prisoner Depression. Thought and Behavior, 6, 21-30.

Kakavand, A., Lebadi, Z., \& Zarei, S. H. (2013). Relationship between Perfectionist and Cognitive Style in Girl Student in Karj City. Journal of Educational Psychology, 27, 27-48.

Lloyd, S., Yiend, J., Schmidt, U., \& Tchanturia, K. (2014). Perfectionism in Anorexia Nervosa: Novel Performance Based Evidence. PLoS ONE, 9, e111697. http://dx.doi.org/10.1371/journal.pone.0111697

Mitchell, J. H., Newall, C., Broeren, S., \& Hudson, J. L. (2013). The Role of Perfectionism in Cognitive Behaviour Therapy Outcomes for Clinically Anxious Children. Behaviour Research and Therapy, 51, 547-554. http://dx.doi.org/10.1016/j.brat.2013.05.015

Mohamdkhani, S. H. (2011). Practice Guideline of Meta-Cognition on Anxiety and Depression. Tehran: Varaye Danesh.

Rekabdar, G. H., \& Soleimani, B. (2011). Identify Typology of Perfectionism and Its Effect beside Gender on Attitude toward Entrepreneurship. Journal of Educational Psychology, 7, 89-105.

Sahraee, A., Khosravi, Z., \& Besharat, M. (2009). Relation between Non-Rational Belief and Positive-Negative Perfectionist in Student of Noshahr. Quarterly Journal of Psychological Studies, 6, 9-42.

Soleimani, B., \& Rekabdar, G. H. (2010). Relationship between Perfectionism Dimensions and Basic Mathematical Skills of students. Journal of Educational Psychology, 1, 1-12.

Soltani, E., Shareh, H., Bahrainian, A., \& Farmani, A. (2013). The Mediating Role of Cognitive Flexibility in Correlation of coping Styles and Resilience with Depression. Pajoohandeh Journal, 18, 88-96. 